\title{
SOFTWARE PROCESS MODELS : A SURVEY
}

Megha V.
Polishwala

Dr. Pravin $\mathrm{H}$. Bhathawala*
Research Scholarcalorx Teachers' Universitynavarangpura, Ahmedabad.

Research Guidecalorx Teachers' Universitynavarangpura, Ahmedabad. ${ }^{*}$ Corresponding Author

Dr. Viral Polishwala Assistant Professorsutex Bank College Of Comp. App. \& Sci.amroli, Surat

ABSTRACT A field of software engineering which is related to development of software product, needs systematic development for large software. This paper specify study of various process models from which systematic development of large software can be developed. Study of various paper and paper review of software process model is explained.

KEYWORDS : Traditional Software Development Models, Agile Software Development, Comparison Study, Reason Of Software Failure.

\section{INTRODUCTION}

An abstract representation of software process is software process model. Selection of software process is an approach by which software process model efficiently selected which is depend upon the given requirement. For systematically coordinating and controlling the tasks, the software process model provides guidance. By using this guidance, development must be performed in order to achieve the end product [90]. Software process model presents a description of framework activities like requirement gathering, planning, analysis and design, implementation, testing and maintenance. All these five activities are performed and modified in software life cycle model.

\section{REVIEW OF LITERATURE}

Existing information is contained by review of literature in which facts, finding, hypothetical, theoretical and practical contributions are consists. This review paper contain various existing methodologies explained by different authors. We are trying an attempt to search for benefits they gained from their lookup and are keen to recognize outcomes so that the model we shall suggest will accommodate similarly improvement.

Rupinder Kaur, Dr. Jyotsna Sengupta described in their paper about various software process models and analysis details with number issues regarding process model failure. Projects run over budget, or some time terminated prematurely etc. are some factors of failure of projects. In this paper, author discuss the current process models and analysis on software failure which shows the requirement of new process model [1] . It presents the factor which causes the project failure: Extracting Requirements, Lack of User Involvement, Team Size, Time Dimension, Fixed Controller, Testing, Poor Quality management [1].Vishwas Massey, Prof. K.J.Satao presents that various SDLC model used for developing different software, they generate successful results and have the fact that circumstance, resources, requirements etc. do vary for developer side and client side. CoCoMo-81 is most simple and easiest mathematical model which generate estimation of effort, development time and staffing is CoCoMo-81 [14].

ArashdeepKaur says important characteristics of software product is schedule, cost and quality and for software quality, reliability and availability are measures. The author presents working plan of S-shaped and schneidewind model which is related to reliability and availability of the software quality and also discuss important uncertain factors : Number of failures and time between failure in the software reliability [7]. Ratnmala R. Raval, Haresh M. Rathod describe various factors affecting on choice of software life cycle models like nature of project, project size, duration, complexity, level and type of expected risk, team size, customer involvement etc. It also describe the comparison of various process model in terms of clear requirement specification, feedback from user, speed to change, predictability, risk identification, loom, cost, usability etc and provide comparison chart of various model like waterfall model, V-shaped model, RAD model, prototype model, incremental model, spiral model and agile model based on usage [10].

Hamza Ahme has described software development lifecycle as the universal model over other models are based and provides the details of SDLC phases, like planning, analysis, design and implementation and importance of each phase which are described in this paper are exist different SDLC process model like incremental model, waterfall model, iterative model, agile development and other process models [4]. Adel Alshamrani and Abdullah Bahattab conclude that there are many existing models for developing system like waterfall model, spiral model and incremental model have same shared properties but they have different advantages and disadvantages and planning for Future work to extend this research to add other models [13].

Abhimanyu Chopra, AbhinavPrashar, ChandreshSaini discuss waterfall model, iteration model, V shaped model and spiral model with its advantages and disadvantages which are developed and used in 1970 to 1999, but now a days, while technology is changed in world, business requirements are changed. The aim of their discussion in this paper is to provide details of different software process model for developing systems according to based on the size of projects and provide comparison between them to show the features and defects of each model [3].Mona Batra, Dr. Archana Bhatnagar gives description of it Requirement engineering is important part of software development, some requirement engineering methods, tools, frameworks and techniques are available for practitioners [9].

Harikrishnan Natarajan, Ram Kumar Somasundaram and Kalpana Lakshmi show the comparison between present models namely waterfall, spiral, RAD, V Model, W Model, etc. with the future models and have resulted in testing by asking a new set of questions to tester [12]. When future testing model arrives, this paper provide all these model with detailed analysis. Future tester model has knowledge of modern tools and methodologies[12]. It include business changes, techno logy trends, test data management, automation, security, pe 
rformance. Success in future testing will improve quality assurance of product [12].

In this paper , Adeeti P. Gosavi, Jayshree B. Pandav presents traditional project management verses modern project management, also described various traditional techniques like waterfall model, spiral model, agile methodologies with its phases to develop a software. It says that preferring agile technology is more effective because it responds to regressive change for software development. In traditional project management, involved steps are initiation, planning, design, monitoring, controlling and closing [5]. MsSuman, Dr. ManojWadhwa says in this paper is how to prevent the defect , to improve software quality [17]. The defect found from software is recorded into database, which is further used for tracking and prioritizing defects [17]. Gurleen Singh, Tamanna discussed agile methodology with their principles and characteristics, how they are over come from the conventional process method, pros and cons using agile methodology [15]. DeepanshuThakral, Mahesh Singh describe the basic understanding of agile methodology which is used for software development [16] . Agile survey results are clearly show popularity of the scrum and DSDM methods for agile methodologies but there are certain challenges for agile methods such as CMMI standards [16].Sanjay Kumar Dubey, Ajay Rana, Arun Sharma focus on usability attributes by reviewing various standards models and he proposed a new environmental integrated usability (EIU) model which describes how various and helps to define quality characteristics [18].

\section{FUTURE WORK}

Selection of appropriate software model according to requirement of client is also play important role in software development. Comparison tables are discussed by the differ ent researchers can give the idea about process model selection. Still after analysis of different research paper in area of software process model, it has been found that there is requirement of software process model in nowadays for software development. Different authors have described their point of view for different software process model. Emphasis is given on the support of traditional as well as software development.

\section{CONCLUSION}

This paper presents the review of different researchers in area of software process model. After analysis, it is found that each model has its own pros and cons. There is need to develop new software process model for the current software development industry. Different reasons of software failures are also discuss by various researchers in their paper.

\section{REFERENCES :}

1. Rupinder Kaur, Dr. Jyotsna Sengupta(2011), "Software Process Models and Analysis on Failure of Software Development Projects", International Journal of Scientific \& Engineering Research Volume 2, Issue 2, February-2011, ISSN 2229-5518.

2. Asmita, Kamlesh, Usha(2015), "REVIEW ON COMPARATIVE STUDY OFSOFTWARE PROCESS MODEL" , International Journal of Science, Technology \& Management ,Volume No 04, Special Issue No. 01, March 2015, ISSN (online): 2394-1537

3. Abhimanyu Chopra, AbhinavPrashar, ChandreshSaini, " Software Projects Models" , INTERNATIONAL JOURNAL OF TECHNOLOGY ENHANCEMENTS AND EMERGING ENGINEERING RESEARCH, VOL 1, ISSUE 4, ISSN 2347 4289

4. Hamza Ahmed, "Software Development", International Journal of Scientific \& Engineering Research, Volume 6, Issue 5,pp.446-450,May-2015, ISSN 22295518

5. Adeeti P. Gosavi, Jayshree B. Pandav, "Analysis of the Different Approaches for Software Project Management", International Journal of Advanced Research in Computer Science and Software Engineering 5(1), January 2015, pp. 421-425, ISSN: 2277 128X

6. Mona Batra, Dr. ArchanaBhatnagar, "Descriptive Literature Review of Requirements Engineering Models", International Journal of Advanced Research in Computer Science and Software Engineering 5(2), February 2015, pp. 289-293, ISSN: $2277128 \mathrm{X}$

7. Arashdeep Kaur, "Comparative Analysis of Reliability Models - Based on Uncertainty Factors", International Journal of Advanced Research in Computer Science and Software Engineering 5(2), February - 2015, pp. 481-
488, ISSN: $2277128 \mathrm{X}$

8. ShubhinderKaur, Er. Amanpreet Kaur Boparai,"Process of Moving from Traditional to Agile software Development: A Review", International Journal of Advanced Research in Computer Science and Software Engineering 5(2), February-2015, pp. 586-591, ISSN: 2277 128X

9. J. Haweliya, M. Sharma, B. Nigam, "Comparative Analysis of Model based Techniques", International Journal of Advanced Research in Computer Science and Software Engineering 5(4), April- 2015, pp. 356-360, ISSN: 2277 $128 \mathrm{X}$

10. Ratnmala R. Raval, Haresh M. Rathod, "Comparative Study of Various Process Model in Software Development", International Journal of Computer Applications, Volume 82-No 18, November 2013, pp. 16-19, ISSN : $0975-8887$

11. Asmita, Kamlesh, Usha, "REVIEW ON COMPARATIVE STUDY OF SOFTWARE PROCESS MODEL", International Journal of Science, Technology \& Management, Volume No 04, Special Issue No. 01, March 2015, pp. 68-75, ISSN (online): 2394-1537

12. Harikrishnan Natarajan, Ram Kumar Somasundaram and Kalpana Lakshmi, "A Comparison Between Present and Future Models Of Software Engineering", IJCSI International Journal of Computer Science Issues, Vol. 10 Issue 2, No 2, March 2013,pp. 47-50, ISSN (Print): 1694-0814| ISSN (Online): 1694-0784

13. Adel Alshamrani and Abdullah Bahattab, "A Comparison Between Three SDLC Models Waterfall Model, Spiral Model, and Incremental/Iterative Model", IJCSI International Journal of Computer Science Issues, Volume 12 Issue 1, No 1, January 2015, pp. 106-111, ISSN (Print): 1694-0814 | ISSN (Online): 1694-0784

14. Vishwas Massey, Prof. K.J.Satao, "Comparing Various SDLC Models And The New Proposed Model On The Basis Of Available Methodology", International Journal of Advanced Research in Computer Science and Software Engineering, Volume 2, Issue 4, April 2012, pp. 170-177, ISSN: 2277 128X

15. Gurleen Singh, Tamanna, "An Agile Methodology Based Model for Software development", International Journal of Advanced Research in Computer Science and Software Engineering, Volume 4, Issue 6, June 2014, pp. $597-$ 602,ISSN: $2277128 \mathrm{X}$

16. DeepanshuThakral, Mahesh Singh, "Study on Agile Methodology: A New Line Towards Business Applications", International Journal of Advanced Research in Computer Science and Software Engineering, Volume 4, Issue 5, May 2014, pp. 570-577,ISSN: 2277 128X

17. MsSuman, Dr. ManojWadhwa, "Enhancing Software Quality Using Defect Prevention Techniques at Design Phase of SDLC". International Journal of Advanced Research in Computer Science and Software Engineering, Volume 4, Issue 6, June 2014, pp. 1446-1452,ISSN: 2277 128X

18. Sanjay Kumar Dubey, Ajay Rana, Arun Sharma, "Usability and Development Environment for Software Applications: An Integrated Model", InternationalJournalofAdvancedResearch in ComputerScience, Volume l, No. 2, July-August 2010, pp. 113-117, ISSN No. 0976-5697 